\title{
THE MORPHOLOGY AND BIOLOGY OF HERPETO- MONAS PATELLAE, N.SP., PARASITIC IN THE LIMPET, PATELLA VULGATA, TOGETHER WITH REMARKS ON THE PATHOGENIC SIGNI- FICANCE OF CERTAIN FLAGELLATES FOUND IN INVERTEBRATES.
}

\author{
By ANNIE POR'TER, D.Sc. LoND., F.L.S. \\ Beit Memorial Research Fellow. \\ (From the Quick Laboratory, Cambridge.)
}

(With 17 Text-figures.)

\begin{tabular}{|c|c|c|c|c|c|c|c|c|}
\hline \multicolumn{9}{|c|}{ CONTENTS } \\
\hline Introduction & $\because$ & & & & & & & 322 \\
\hline Observations on & & & & $\because$ & $\cdots$ & & $\cdots$ & \\
\hline Observations on & $7 \operatorname{lng}$ & Herpet & ana & itellae & $\cdots$ & $\cdots$ & $\cdots$ & 323 \\
\hline Morphology .. & . & . & . & $\ldots$ & . & . & . & 323 \\
\hline Multiplication & . & $\cdots$ & $\cdots$ & . & . & . & . & 325 \\
\hline Nutrition $\quad$. & . & $\ldots$ & . & .. & . & . & . & 326 \\
\hline \multicolumn{2}{|c|}{ Mode of Transmission } & $\cdots$ & . & .. & .. & . & .. & 326 \\
\hline \multicolumn{2}{|c|}{ Systematic Position } & . & . & . & .. & .. & .. & 327 \\
\hline \multicolumn{9}{|c|}{ Remarks on the pathogenic significance of certain Flagellates } \\
\hline \multicolumn{3}{|c|}{ found in Invertebrates. } & . & $\cdots$ & & . & & 327 \\
\hline References .. & .. & . & . & . & .. & . & . & 329 \\
\hline
\end{tabular}

Introduction.

MANY herpetomonads have been recorded from various insects belonging chiefly to the Diptera and Hemiptera, but until the present instance, members of this genus of flagellates have not been found in the Mollusca and very few in other Invertebrata. Also the habitat of the herpetomonads has usually been either the main alimentary tract or the haemocoel of their hosts. Digestive glands hitherto have not been recorded as being infected.

Recently, during examinations of a number of the edible limpet, Patella vulgata, I was fortunate in finding one infected with a small number of minute herpetomonads, the alimentary tract and digestive 


\section{A. Porter}

gland (or "liver") of the molluse being infected. Other limpets were examined for herpetomonads, about fifty in all, and eight per cent. of the total examined were found to be slightly infected. The range of the genus Herpetomonas is thus extended to the Mollusca, and the digestive gland is added to the organs of a host that may harbour such parasites. The name Herpetomonas patellae is proposed for this new flagellate.

I have much pleasure in thanking Professor Herdman and $\mathrm{Mr} \mathrm{H}$. C. Chadwick for their kindness in facilitating my researches at Port Erin, Isle of Man, in Nov. 1913, when the parasite was found. Mr Chadwick greatly aided me in obtaining material. Observations were continued near Brighton in May 1914. Preparations were further studied and the research was completed in Cambridge in the laboratory of Professor Nuttall, to whom my thanks are due.

\section{Observations on living Herpetomonas patelLae.}

The flagellate herpetomonads appear as very small, somewhat refractile organisms and move jerkily, the body being sharply flexed and then straightened and the flagellum lashing vigorously. Swirling movements, suggestive of those of a boomerang, are common. The flagellum is thick and is easily seen in life. It is often as long as the body. The flagellar end is forwardly directed in movement. The parasites showed no tendency to collect in groups and neither division rosettes nor aggregations were observed. A few dividing forms were watched and multiplication by simple longitudinal fission was the only mode of increase seen. A few young flagellates were found in the stomach of the limpet; full grown forms were most abundant in the "liver." A few were observed in the rectum and faeces.

The part of the "liver" adjacent to the stomach also contained ovoid, non-flagellate forms of the parasite. Some of these in a fresh preparation were watched for several hours, and the gradual production of a flagellum with subsequent elongation of the body was seen in individual cases. The flagellum was often formed before the distal or posterior end of the body lengthened. A few thicker walled postflagellate forms were found in the distal end of the "liver," as well as in the rectum.

\section{Morphology.}

The morphology was studied both in the living organism and in stained preparations. Smears of the gut contents and of the digestive 
gland of the limpet were fixed wet in Bouin's fluid, in osmic acid vapour followed by absolute alcohol, or in formalin vapour. They were stained by Delafield's haematoxylin, by glycerine haematein or by Giemsa's solution. Fixation by Bouin's fluid, followed by haematoxylin staining was best.

The parasite exhibits the usual three phases common among flagellates in its life-cycle.

A. Pre-flagellate forms. The pre-flagellates (Fig. 1) are ovoid bodies measuring from $2 \mu$ to $3 \mu$ long, and are about $1 \mu$ to $1 \cdot 5 \mu$ broad. The nucleus is oval, showing sometimes a central karyosome (Fig. 2), but more often having the chromatin evenly distributed (Fig. 1).

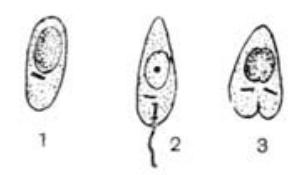

Figs. 1-3. Herpetomonas patellae. Pre-flagellate. developing young flagellate and dividing pre-flagellate forms. $\times 3000$.

The blepharoplast is barlike and homogeneous. Some specimens showed a chromatophile area from which the flagellum develops. The growing pre-flagellate shows an elongation of the end near the blepharoplast. A chromatoid thread is gradually differentiated, which pushes the periplast forward and then projects as a free flagellum (Fig. 2).

B. Flagellate forms. The flagellates (Figs. 4-10) measure from $5 \mu$ to $7 \mu$ in body length and are about $1 \mu$ broad. The free flagellum is sometimes somewhat longer than the lanceolate body (Figs. 7-10).

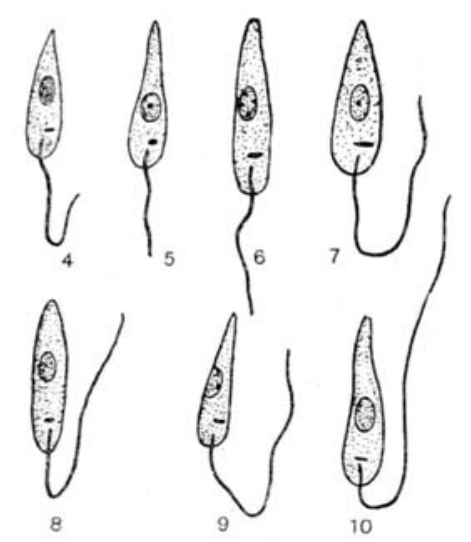

Figs. 4-10. Herpetomonas patellae. Various aspects of the flagellate stage. $\times 3000$. 
The flagellar end is rather blunt (Fig. 6). The posterior or aflagellar end is more pointed in some specimens (Figs. 7, 9), but is not markedly so in others (Figs. 6, 8). The nucleus exhibits the same two types as are seen in the pre-flagellates, namely, those with the chromatin distributed in granules (Figs. 6, 10) and those with it concentrated as a karyosome (Figs. 5, 7). In forms about to divide, the nucleus is always granular in character and the karyosome is not seen.

C. Post-flagellate forms (Figs. 11-14). These resemble the preflagellates and are about the same size, but have somewhat thicker

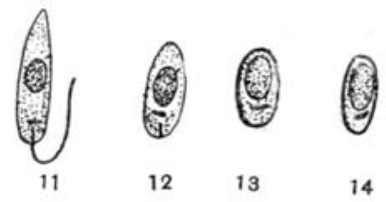

Figs. 11-14. Herpetomonas patello. Development of the post-flagellate form. $\times 3000$.

cyst walls. The nucleus most frequently shows homogeneous chromatin (Figs. 11-14), but occasionally a karyosome is present. The blepharoplast usually is near the nucleus (Figs. 12-14); in a few specimens it was superimposed.

The post-flagellate form of $H$. patellae is derived from the flagellate by the retrogression and absorption of the flagellum (Fig. 11), accompanied by the gradual concentration of the body cytoplasm around the nucleus. The wall at first is gelatinous and swells slightly if warm distilled water be added to the preparation. No swelling occurs in preparations made with physiological salt solution at room temperature. The gelatinous cyst wall gradually contracts and forms a varnish-like sheath in the final resting condition (Figs. 12-14).

\section{Multiplication.}

Multiplication occurs by binary fission of either the pre-flagellate (Fig. 3) or flagellate (Figs. 15-17) parasites. The division of the preflagellate (Fig. 3) is initiated by that of the blepharoplast. The nucleus gradually constricts into two. The cytoplasm segregates to either side of the body so that a continuous vacuole appears from end to end of the pre-flagellate. A cleft is next seen near the blepharoplast and gradually extends backwards to the posterior end. Slight movements of the body occur. No division rosettes of the pre-flagellates of H. patellae were found. 
The division of the flagellate forms of $H$. patellae (Figs. 15-17) follows on the same lines as that of $H$. jaculum, $H$. lygaei, $H$. pediculi and other herpetomonads. The order of division is blepharoplast, flagellum,
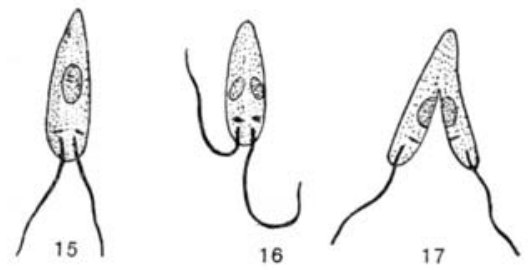

Nigs. 15-17. Herpetomonas patellae. Dividing forms. $\times 3000$.

nucleus, cytoplasm. Division of the flagellum, which may be unequal, was observed in the living organism. No budding phenomena, such as those described by some authors for the flagella of dividing $H$. muscae domesticae, have been observed. No division rosette formation has been seen in $H$. patellae, nor were aggregation rosettes found. Perhaps this was due to the scanty infection encountered.

\section{Nutrition of $\mathrm{H}$. Patellat.}

Apparently the larger number of the herpetomonads were nourished on the liver fluid surrounding them, which they absorb by osmosis. There was no evidence of the existence of a cytostome, cytopharynx or cytopyge in $H$. patellae. A recent suggestion that the myoneme striations of some herpetomonads were really the edges of a cytopharynx is inaccurate so far as H. patellae and H. jaculum are concerned. Though continuous observations were made, no organised substances such as bacteria or food particles, either in process of ingestion or digestion, were seen in the body of $H$. patellae. Nutrition seems to be by passive absorption of fluid food by the general body surface, and resembles that of other insect flagellates and such organisms as trypanosomes.

\section{Mode of Transmission.}

A few post-flagellate forms were obtained from the anal portion of the gut of the limpet. Flagellate forms were not common in the gut, though a few flagellates were seen in the rectum and freshly shed faeces. The occurrence of post-flagellate forms in faecal matter suggests that the mode of infection is contaminative. The paucity of infected material prevented further experimental work being undertaken. The flagellates 
doubtless gain access to the digestive gland ("liver") by passing along the numerous small ducts that finally unite into one leading from the "liver" to the stomach of the limpet.

\section{Systematic Position.}

The flagellate parasitic in Patella vulgata is a member of the genus Herpetomonas as originally defined. It is considered to be a new species, H. patellae. It shows the following characteristics among others. H. patellae is much smaller than any other Herpetomonas yet described, its body being only $5 \mu$ to $7 \mu$ long. The relatively large size of the nonflagellate stages of the organism is not common among other herpetomonads. The movements of $H$. patellae are more jerky than those of most other herpetomonads and the "boomerang" movement is unlike that described for any other species, so far as I am aware. Its occurrence in the digestive gland of a molluse is believed to be unique at present.

\section{Remarks on the pathogenic significance of certain Flagellates found in Invertebrates.}

During the last few months, thanks to the interesting investigations of Laveran and Franchini, the importance of herpetomonads and Crithidia has greatly increased from the pathogenic point of view. Laveran and Franchini's first series of experiments (Sept. 1913) showed that Herpetomonas clenocephali (Fantham), parasitic in the gut of the dog flea, Ctenocephalus canis, could be inoculated intra-peritoneally and otherwise into white mice with fatal results. Leishmaniform parasites were found in the blood and internal organs of the mice, especially in the liver. A very few flagellate parasites only were seen in the inoculated vertebrate. Rats and a dog were also inoculated. The dog died, leishmaniform parasites being found in the internal organs. The infection could be maintained by successive inoculations into clean vertebrates.

Similar experiments were made with Crithidia fasciculata (Léger), parasitic in the gut of Anopheles maculipennis. The experiments began with the successful inoculation of the contents of the digestive tract of parasitised Anopheles into rats and mice.

Further experiments were undertaken with Herpetomonas pattoni (Swingle), parasitic in the gut of the rat flea, Ceratophyllus fasciatus. White rats and white mice became infected when kept in contact with numerous parasitised rat fleas. It was then shown that the mode of 
infection of the rodents was by eating the parasitised rat fleas, the incubation period being two to three weeks-that is, longer than by intra-peritoneal inoculation.

Mice were also infected by way of the digestive tract with Crithidia melophagia (Flu), a parasitic flagellate of the sheep ked, Melophagus ovinus.

The authors' last series of experiments (July 1914) showed that mice can be infected by ingesting the faeces of rat fleas containing H. pattoni; also that inoculation of Crithidia fasciculata into a white mouse produced cutaneous lesions resembling those of Oriental Sore. As was stated by Fantham and Porter (Dec. 1913), when commenting on the earlier work of Laveran and Franchini, these experiments signify "leishmaniasis in the making." The spleen was found to be enlarged in the various experimentally infected animals. Flagellate parasites were very rare indeed in the experimental animals and were even absent in some cases, but leishmaniform and uninucleate rounded elements occurred in the red blood corpuscles and free leishmaniforms were observed. Further, it is possible that the canine kala-azar occurring in the Mediterranean region is really a canine herpetomoniasis due to Herpetomonas ctenocephali.

These experimental results should be compared with certain established facts, of which two may be specially mentioned: (1) The various species of Leishmania in culture grow into herpetomonad flagellates. (2) Franchini (1913) described a herpetomonad parasite obtained post mortem from a human subject who had long lived in Brazil. ' $\mathrm{He}$ named the parasite Haemocystozoon brasiliense, though as Brumpt (1913) says, it might have been placed, probably, in the genus Herpetomonas. A third point, which is an inference from Laveran and Franchini's experiments, and is mentioned by the authors themselves, is that Leishmania and the trypanosomes probably arose from the flagellates of invertebrates. Fourthly, it should be remembered that leishmaniform elements have been described by Moore and Breinl (1907) and by Fantham (1911) as part of the life cycle of trypanosomes in vertebrate hosts. These leishmaniform elements or "latent bodies" occur in the internal organs. Their occurrence serves further to point out the close genetic and even phylogenetic relationship between Herpetomonas, Leishmania, Crithidia and Trypanosoma.

As Herpetomonas patellae occurs in an edible invertebrate, it may be remarked that such flagellates are possibly not without pathogenic properties, if they should find their way alive in sufficient numbers 
into a vertebrate. Without wishing to be an alarmist, it is well to remember the pathogenic importance of herpetomonads and Crithidia, originally occurring as natural parasites of invertebrates, but possessing the power of adaptation to life in the sanguineous organs of vertebrates.

\section{REFERENCES.}

BRUmpt, E. (1913). À propos de l'Haemocystozoon brasiliense de Franchini. Bull. Soc. Path. Exot., vi, pp. 377-380.

Fantham, H. B. (1911). The Life History of Trypanosoma gambiense and T. rhodesiense as seen in Rats and Guinea-pigs. Proc. Roy. Soc., B, Lxxxm, pp. 212$227,1 \mathrm{pl}$.

Fanteam, H. B. (1912). Herpetomonas pediculi, nov. spec., parasitic in the Alimentary Tract of Pediculus vestimenti, the Human Body Louse. Proc. Roy. Soc., B, LXxxIV, pp. 25-40, 1 pl.

Fantram, H. B. (1912). Some Insect Flagellates and the Problem of the Transmission of Leishmania. Brit. Med. Journ., II, Nov. 2, pp. 1196-1197.

Fantham, H. B. and Porter, A. (1913). Herpetomonas stratiomyiae, n. sp. Annals Trop. Med. and Parasitol., vi, pp. 609-620, 1 pl.

Franchinr, G. (1913) Un nouveau protozoaire parasite de l'homme provenant du Brésil. Bull. Soc. Path. Exot., vi, pp. 156-158.

Franchint, G. (1913). Nouvelle contribution à l'étude de Haemocystozoon brasiliense. Bull. Soc. Path. Exot., vi, pp. 333-336.

Laveran, A. et Franchin, G. (1913). Infections expérimentales de la souris par Herpetomonas ctenocephali. C. R. Acad. Sci., Paris, t. 157, pp. 423-426.

Laveran, A. et Franchint, G. (1913). Infections expérimentales de Mammifères par des Flagellés du tube digestif de Ctenocephalus canis et d'Anopheles maculipennis. C. R. Acad. Sci., Paris, t. 157, pp. 744-747.

Laveran, A. et Franchint, G. (1914). Infection naturelle du rat et de la souris au moyen de puces de rat parasitées par Herpetomonas pattoni. C. R. Acad. Sci., Paris, t. 158, pp. 450-453.

Laveran, A. et Franchint, G. (1914). Infection de la souris au moyen des Flagellés de la puce du rat, par la voie digestive. $C . R$. Acad. Sci., Paris, t. 158, pp. 770-772.

Laveran, A. et Franchini, G. (1914). Infections de Mammifères par des flagellés d'invertébrés. Bull. Soc. Path. Exot., vIr, pp. 605-612, 4 figs.

LÉGER, L. (1902). Sur un flagellé parasite de l'Anopheles maculipennis. Compt. Rend. Soc. Biol., LIV, pp. 354-356.

Moork, J. E. S. and Breinl, A. (1907). The Cytology of the Trypanosomes, Part 1. Annals Trop. Med. and Parasitol., I, pp. 441-480, 5 pls.

Porter, Anvie (1909). The Life Cycle of Herpetomonas jaculum (Léger), parasitic in the Alimentary Tract of Nepa cinerea. Parasitology, ח, pp. 367-391, 1 pl.

PorTer, ANNIF (1910). The Structure and Life-history of Crithidia melophagia (Flu), an Endoparasite of the Sheep Ked, Melophagus ovinus. Quart. Journ. Microsc. Sci., Lv, pp. 189-224.

Swingl,e, L. D. (1911). The Transmission of Trypanosoma leursi by rat-fleas (Ceratophylius sp. and Pulex sp.), with short descriptions of three new Herpetomonads. Jour.?. Infect. Diseases, VII, pp. 125-146. 